\title{
The effect of key parameters on the design of an optimized caes power plant
}

\author{
M. Khalaji Assadi1, a, S.R. Shamshirgaran ${ }^{2}$ and S. Defaee Rad $^{3}$ \\ ${ }^{1}$ Universiti Teknologi PETRONAS, Department of Mechanical Engineering, 31750 Tronoh, Perak, Malaysia \\ ${ }^{2}$ Shahid Beheshti University, ACE, Department of Mechanical and Energy Engineering, Tehran, 16765-1719, Iran \\ ${ }^{3}$ Tara Tarh Engineering and Technological Company, Metallic Process Department, Tehran, 14389, Iran
}

\begin{abstract}
Due to the significant variations in electricity generation and its demand, the power plant owners are encountered with challenges of economic operation. Among all, Compressed air energy storage (CAES) technology has proposed itself as a reliable and efficient solution to match the two sides. This paper deals with a modeled compressed air energy storage power plant which has been optimized thermodynamically through an efficient genetic algorithm code. The results of this optimized model, considered as the base case, show that the power plant is technically and financially justifiable. In order to obtain a more tangible realization, it is necessary to verify the results against the variation of key parameters. In this study, the sensitivity analysis is performed based on main parameters including plant loading and ambient condition and the resultant trends of each case are presented. This approach will help the designers to analyze the quality of their designs in different situations.
\end{abstract}

\begin{tabular}{|llll|}
\hline \multicolumn{4}{|c|}{ Nomenclature } \\
$B$ & net annual benefit [\$/kW-yr] & $w$ & specific work [kJ $/ \mathrm{kg}]$ \\
$c_{p}$ & specific heat at constant pressure & $\sigma$ & pressure loss factor \\
$H_{d}$ & dimensionless discharging duration & $\eta_{\mathrm{c}}$ & compressor efficiency \\
$k$ & the ratio of specific heats & $\eta_{\mathrm{cxlm}}$ & $\eta_{\mathrm{c}} \eta_{\mathrm{ex}} \eta_{\mathrm{elm}}$ \\
$m$ & number of heating stages & $\eta_{\mathrm{elm}}$ & electro-mechanical efficiency \\
$n$ & number of cooling stages & $\eta_{\mathrm{ext}}$ & external thermal efficiency \\
$p$ & pressure [bar] & $\eta_{\mathrm{it}}$ & turbine isentropic efficiency \\
$q_{f}$ & specific heat from combustion & $\eta_{\mathrm{m}}$ & turbine mechanical efficiency \\
$r_{m t}$ & maximum temperature ratio & $\eta_{\mathrm{g}}$ & generator Electrical efficiency \\
$r_{p}$ & pressure ratio & $\eta_{\mathrm{t}}$ & turbine efficiency \\
$r_{s t}$ & storage temperature ratio & $\eta_{\mathrm{telm}}$ & $\eta_{\mathrm{t}} \eta_{\mathrm{elm}}$ \\
$R$ & terminal isentropic temperature ratio & $\eta_{\mathrm{th}}$ & thermal efficiency \\
$T$ & Temperature [K, $\left.{ }^{\circ} \mathrm{C}\right]$ & $\varepsilon_{\mathrm{RC}}$ & recuperator effectiveness \\
\hline
\end{tabular}

\section{Introduction}

Electrical Energy Storage (EES) refers to a process of converting electrical energy from a power network into a form that can be converted back to electrical energy when needed [1]. Such a process enables electricity to be produced at times of low demand, low generation cost or from intermittent energy sources and to be used at times of high demand, high generation cost or when no other generation means is available.

With the rapid development of the international electrical energy storage industry, over 400 energy storage projects had already been established worldwide by 2012 , these projects have been widely used for power generation, transmission and distribution, renewable energy integration and ancillary services [2]. Compressed Air Energy Storage (CAES) is a type of commercialized EES technology, which can provide above $100 \mathrm{MW}$ of power output via a single unit as well as having bulk energy storage capacity [3]. CAES can work with intermittent renewable energy applications, especially in wind power, to smooth the power output, which have

\footnotetext{
a Corresponding author: morteza.assadi@petronas.com
} 
attracted much attentions from academic researchers and industrial sectors as described in [4]. The major barrier to implementing large-scale CAES plants is identifying appropriate geographical locations which will decide the main investment cost of the plant. Examples of commercially successful CAES plants are the Huntorf power plant (built in Germany in 1978) and the McIntosh power plant (built in the United States in 1991).

A comparison of different operation strategies for a given CAES plant is presented by Lund et al [5]. Two practical strategies were compared with the optimal strategy, identified by the previous knowledge of future spot market prices, and it is shown that with these strategies the CAES plant can be expected to earn 80-90 per cent of the optimal earnings.

A comparative analysis of CAES, Gas Turbines and HPS has been performed by Najjar and Zaamout [6], evidencing the advantages of CAES systems, particularly for the dry regions.

A comparison between gas turbines and compressed air energy storage as competitors for supplemental generation has been performed by Greenblatt et al [7]. It has been shown that the wind+CAES system has the lowest dispatch cost of the alternatives considered (lower even than for coal power plants) above a green house gas (GHG) emissions price of \$35/tCequiv., with good prospects for realizing a higher capacity factor and a lower total cost of energy than all the competing technologies over a wide range of effective fuel costs.

The present study deals with a modeled compressed air energy storage cycle which has been optimized thermodynamically by using a genetic algorithm. The model can be utilized for investigating the different hybrid applications. The modeling approach and optimization process was presented in the previous work [8]. Here the main points and results which have been used for present work are presented. This paper aims at different conditions at which a CAES may be operated. In other words, the effect of off-design condition parameters on the plant performance, which would help the plant designers and operators to make the best decisions, has been studied.

\section{Plant description}

Figure 1 shows a schematic diagram of a CAES system [1]. CAES works on the basis of conventional gas turbine generation. It decouples the compression and expansion cycles of a conventional gas turbine into two separated processes and stores the energy in the form of elastic potential energy of compressed air.

During low demand, energy is stored by compressing air into an air tight space, typically 4.0-8.0 MPa. In order to extract the stored energy, compressed air is drawn from the storage vessel, heated and then expanded through a high pressure turbine (HPT), which captures some of the energy in the compressed air. The air is then mixed with fuel and combusted with the exhaust and expanded through a low pressure turbine (LPT). Both the high and low pressure turbines are connected to a generator to produce electricity.

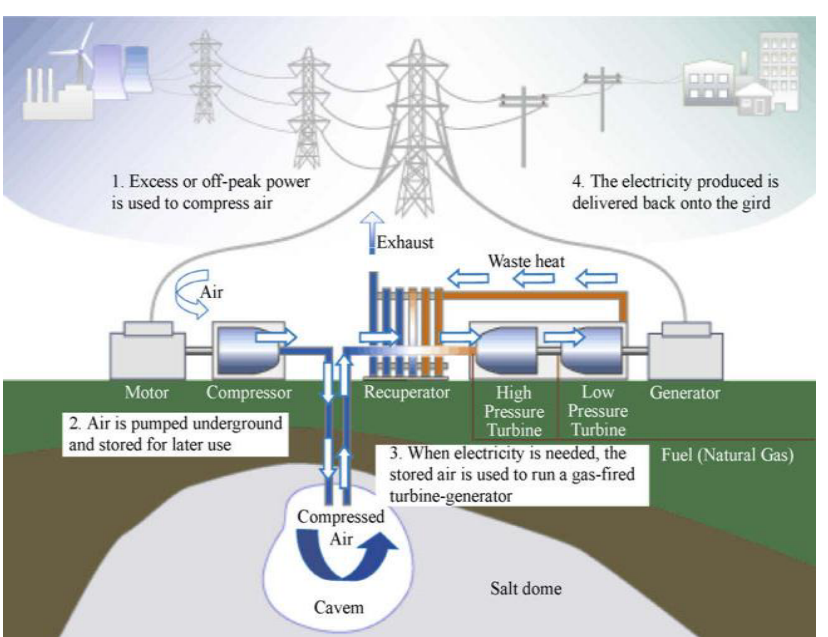

Figure 1. Schematic diagram of CAES plant [1].

The basic thermodynamic governing equations of compression and expansion processes are as following [9]:

$$
\begin{gathered}
R=T_{2} / T_{1}=\left(p_{2} / p_{1}\right)^{(k-1) / k}=r_{p}^{(k-1) / k} \\
w_{c}=\frac{c_{p} T_{1}}{\eta_{c} \eta_{e l m}} n\left(\sigma_{c} R^{1 / n}-1\right), \\
w_{t}=c_{p} T_{1} \eta_{t} \eta_{e l m} r_{m t} m\left(1-\frac{\sigma_{t}}{R^{1 / m}}\right) \\
q_{f}=c_{p} T_{1} r_{m t}\left\{\frac{\sigma_{h}}{R}-\varepsilon_{R C}\left[1+\eta_{t}\left(\frac{\sigma_{h}}{R}-1\right)\right]-\right. \\
\frac{r_{s t}}{r_{m t}}\left(1-\varepsilon_{R C}\right)+m\left[1-\frac{\sigma_{t}}{R^{1 / m}}\right] \\
\eta_{t h}=\frac{w_{t}}{w_{c} / \eta_{e x t}+q_{f}}
\end{gathered}
$$

The waste heat of the exhaust is potentially captured via a recuperator before being released.

\section{Modeling the CAES plant cycle}

One of the key issues in the development of a CAES plant is to design its thermodynamic cycle in the optimum condition. In order to maximize the CAES profit, power should be stored in off-peak hours and be delivered to the grid in peak hours. The profit is obtained from the difference between the price of energy in offpeak hours with the price of energy in peak hours. The CAES cost should also be taken into consideration because using either large or small amount of storage can reduce the total profit. The objective function is defined so that it determines the CAES size corresponding to the maximum profit. Therefore the objective function should be as:

$$
\operatorname{MAX}(\mathrm{NP})=\operatorname{Re}-\mathrm{C}
$$

In the above equation NP stands for the total net profit or benefit, $R e$ shows the revenue obtained from selling the power in peak hours and $C$ stands for the cost of not selling the power in off-peak hours and storing it and the cost of CAES. 
The objective function is in fact a cost-benefit function, which is optimized by genetic algorithm (GA). The optimization tool (GA) of MATLAB software has been applied for this purpose. In this way the optimum value of design parameters is obtained and can be used in design and modeling procedures. The optimization result includes the optimum values as: $r_{m t}^{*}=4.91, R^{*}=3.2$,

$$
H_{d}^{*}=0.79, \varepsilon_{R C}^{*}=0.76, m^{*}=2, n^{*}=4 \text {. }
$$

The thermodynamic model used in this analysis is based on information from [8] to determine the physical characteristics of the optimized CAES system. The thermodynamic process in each combustion chamber and gas turbine is regarded as an adiabatic process. Figure 2 shows the thermodynamic model of CAES plant.

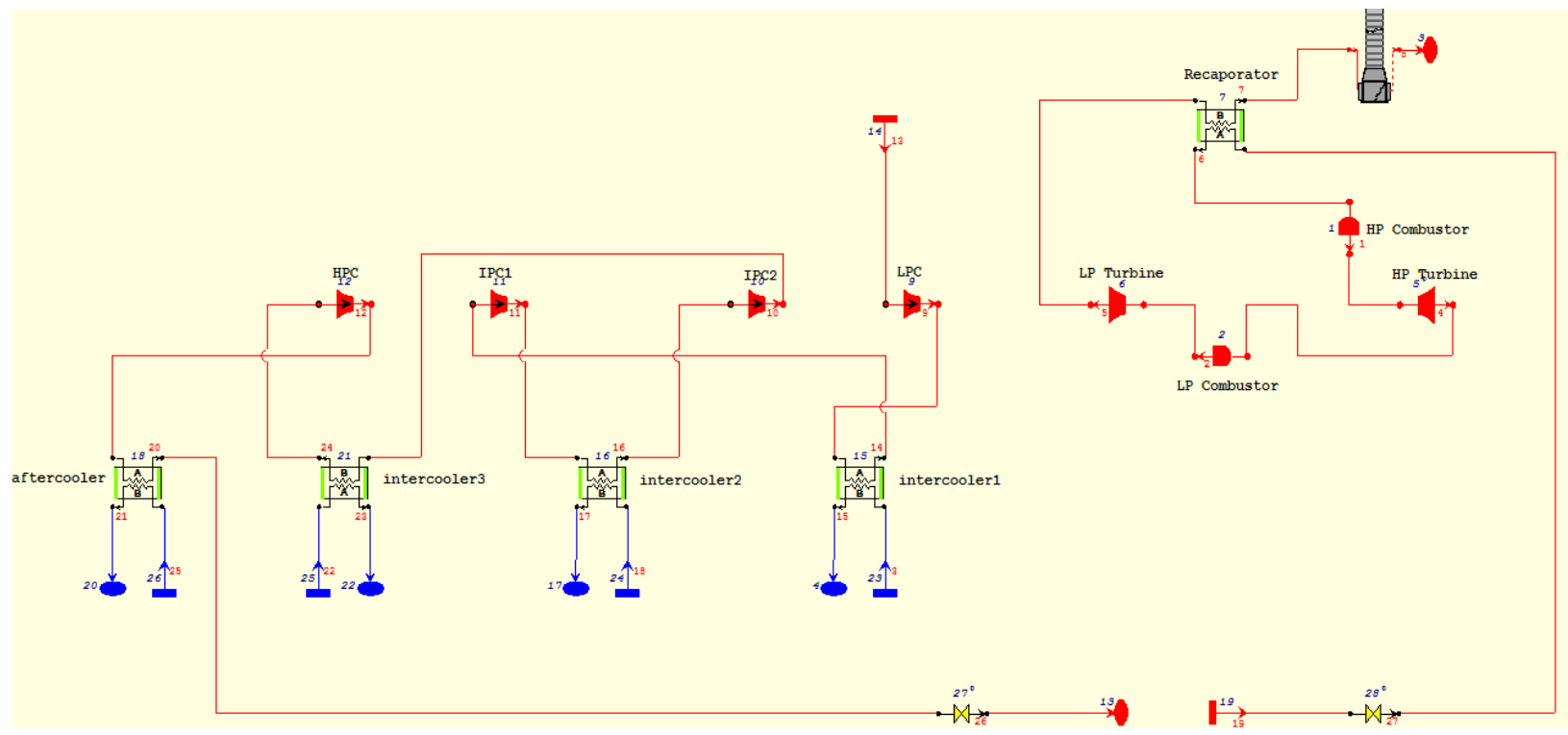

Figure 2. The modeled CAES plant [8]

In the CAES cycle, the energy storage subsystem comprises four compressors, four coolers, and a cavern with a constant volume. The air is cooled to $89.5^{\circ} \mathrm{C}$ in both the intercoolers and the aftercooler. Water is the cooling medium, and counter flow is adopted in the cooler. The air is compressed to approximately 59 bar on average and stored in a cavern. The electricity-generating subsystem is built based on gas turbine units. The compressed air released from the air storage cavern is mixed with natural gas in the combustion chamber. Before flowing into the HP turbine, the mixed gas is heated to $1190^{\circ} \mathrm{C}$. Similarly, a certain amount of natural gas is also mixed with the gas exhausted from the HP turbine. Then, the mixed gas is heated to $1160{ }^{\circ} \mathrm{C}$ before entering the LP turbine.

\section{Main results}

The main thermodynamic parameters including pressure, temperature, flow, and enthalpy for major components corresponding to the points indicated in Figure 2 are listed as base case in Table 1 .

The compression to 58.73 bar requires $519 \mathrm{~kJ}$ energy per $\mathrm{kg}$ of air. After efficiency losses, the recoverable expansion energy is $1025 \mathrm{~kJ}$ per $\mathrm{kg}$. The size of the energy storage depends on the recoverable work per unit mass of air stored. The amount of work per $\mathrm{kg}$ of air stored is equal to the total input during compression and depends on the actual time needed to the charge of reservoir. Reservoir discharge (production) and charge (compression) timing and subsequently the capacity of air storage are determined based on electrical network studies and requirements.

Table 1. The main thermodynamic parameters of CAES plant.

\begin{tabular}{|c|c|c|c|c|}
\hline $\begin{array}{l}\text { parameter } \\
\text { component }\end{array}$ & $\begin{array}{l}\text { Press. } \\
\text { (bar) }\end{array}$ & $\begin{array}{l}\text { Temp. } \\
\left({ }^{\circ} \mathrm{C}\right)\end{array}$ & $\begin{array}{c}\text { Flow } \\
(\mathrm{kg} / \mathrm{s})\end{array}$ & $\begin{array}{c}\text { Enthalpy } \\
(\mathrm{kJ} / \mathrm{kg})\end{array}$ \\
\hline LP Compressor inlet & 0.998 & 22.2 & \multirow{8}{*}{452.2} & -2.83 \\
\hline LP Compressor outlet & 2.78 & 133 & & 110.36 \\
\hline IP Compressor1 inlet & 2.76 & 75.86 & & 51.71 \\
\hline IP Compressor1 outlet & 7.62 & 205.4 & & 185.15 \\
\hline IP Compressor 2 inlet & 7.58 & 76.04 & & 51.5 \\
\hline IP Compressor 2 outlet & 21.86 & 212.3 & & 191.91 \\
\hline HP Compressor inlet & 21.43 & 79.02 & & 50.52 \\
\hline HP Compressor outlet & 58.73 & 204.9 & & 183 \\
\hline Recuperator air inlet & 50.2 & 31.21 & 106.8 & -0.2 \\
\hline HP Combustor inlet & 44.83 & 368.9 & 106.8 & 353.84 \\
\hline HP Combustor outlet & 43.10 & 1190 & \multirow{2}{*}{109.2} & 1362.76 \\
\hline HP Turbine outlet & 16.33 & 952.8 & & 1061.38 \\
\hline LP Combustor outlet & 15.7 & 1160 & \multirow{3}{*}{109.9} & 1340.9 \\
\hline LP Turbine outlet & 1.071 & 579.5 & & 616.35 \\
\hline Stack inlet & 1.0008 & 278.5 & & 272.37 \\
\hline
\end{tabular}

\section{Off- design performance}

Plant designers and operators always need to evaluate its performance in different operating condition because the variation of plant performance based on the key parameters yields a good view to make the better strategic decisions. Therefore it is important to have a good sense of CAES key parameters effect on the plant performance. 


\subsection{Loading effect}

Plant heat rate is a performance indicator that all manufacturers rely on it for attracting the client's interest. Heat rate value of typical CAES plants has reported in the range of $4200-4800 \mathrm{~kJ} / \mathrm{kWh}$ [10]. Figure 3a shows the variation of modeled plant heat rate for partial loads. As can be seen, the value of plant heat rate increases when the load decreases, however the variation range of heat rate is not so wide. That is why said CAES plants work efficiently even in the part load and it is one of the main advantages of CAES cycles rather than conventional gas turbines.

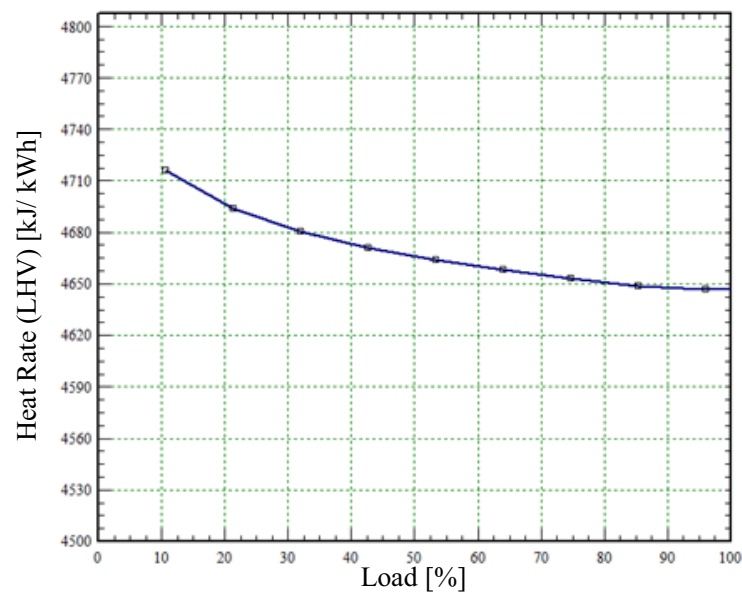

Figure 3a. Plant heat rate based on its load percentage

It is obvious that the optimum or design value of CAES heat rate achieved in full load i.e. $4647 \mathrm{~kJ} / \mathrm{kWh}$ for the model. Figure $3 \mathrm{~b}$ illustrates the air flow through the expander train for the different partial loads.

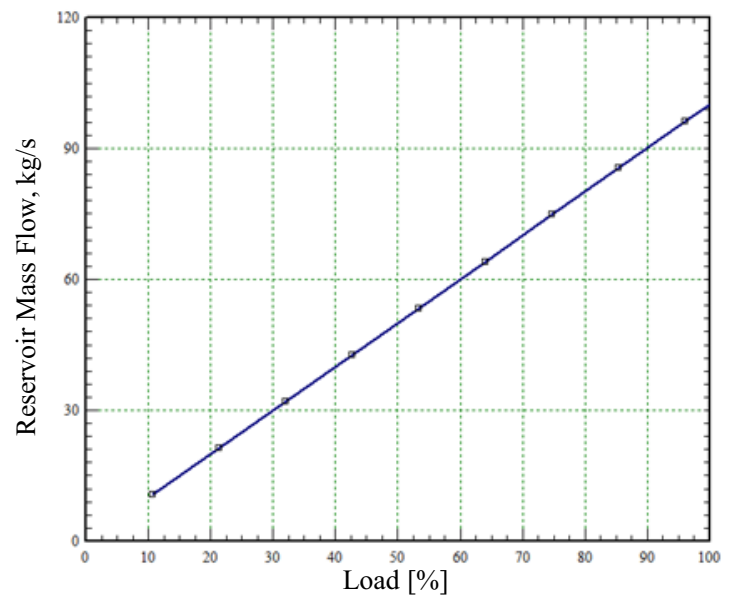

Figure 3b. Air flow rate through the expanders based on load percentage

The combination of both curves results in Figure $4 \mathrm{a}$ which has been presented along with the real corresponding chart, Figure $4 \mathrm{~b}$, from the most famous manufacturer of CAES i.e. Dresser- Rand Co [10].

The model's curves closely match the real ones and this verifies the modeling.

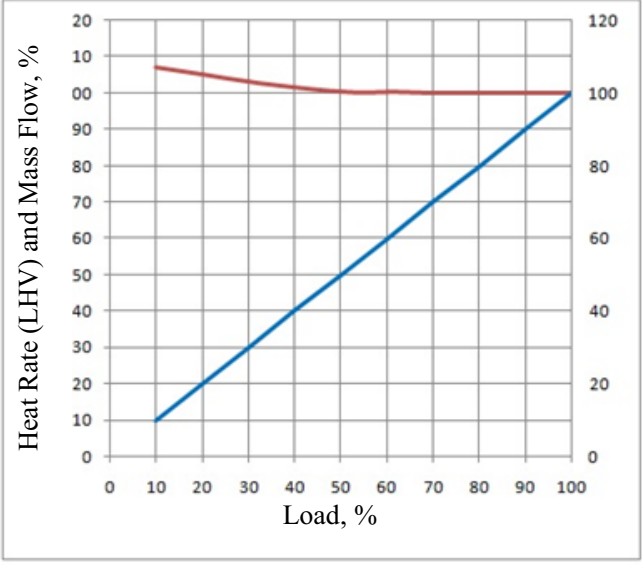

Figure 4a. Model heat rate and air mass flow based on plant load\%

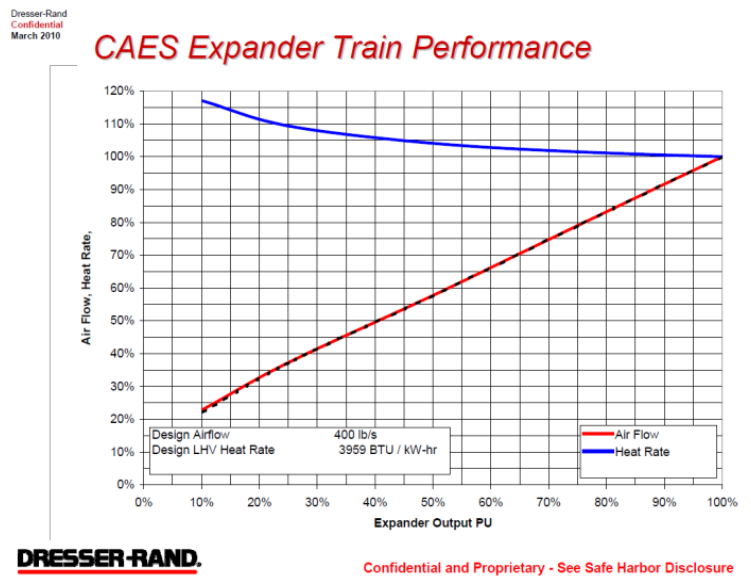

Figure 4b. Real heat rate and air mass flow through the expanders based on load\% [10]

\subsection{Ambient temperature effect}

Figures $5 \mathrm{a}$ and $5 \mathrm{~b}$ confirm that unlike the conventional gas turbines, the ambient temperature does not affect so much the power consumption of CAES compressor train.

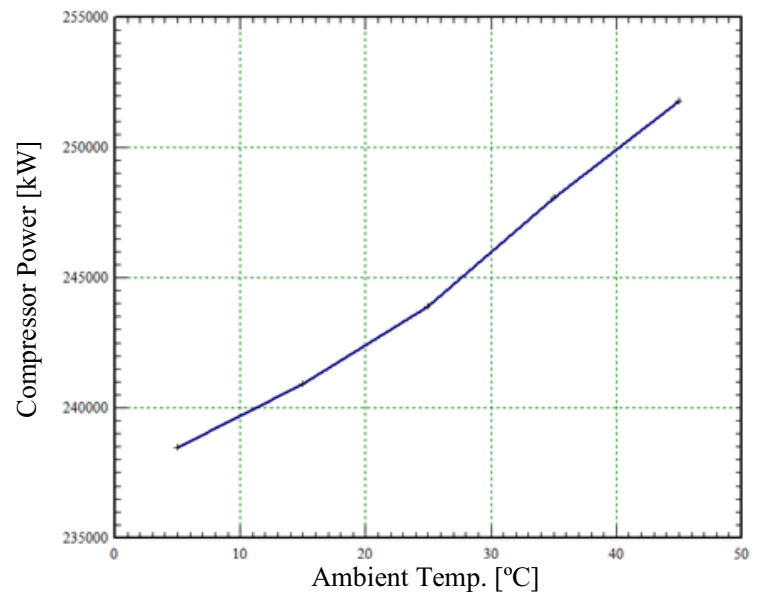

Figure 5a. Total compression power based on ambient temperature 


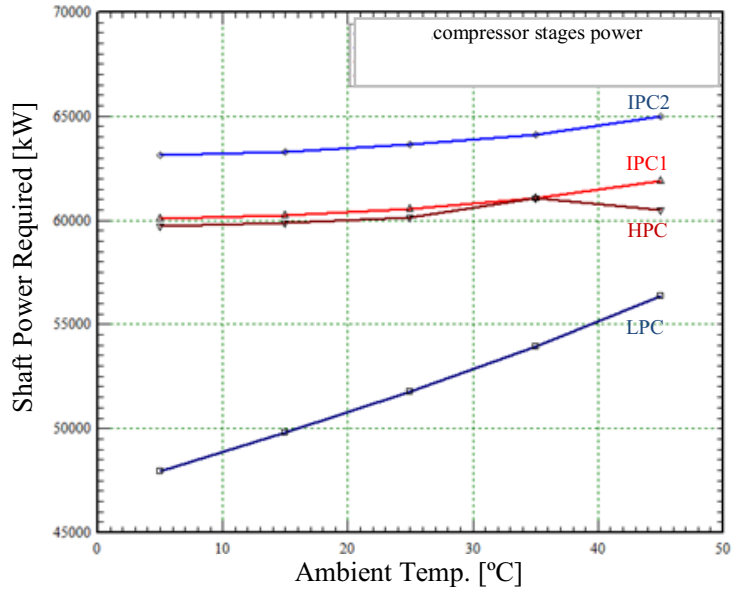

Figure 5b. Shaft power of compressor stages based on ambient temperature

A fifty percent increase of ambient temperature results in almost two percent more consumption work. Moreover the ambient temperature does not have any effect on expander train because compressor and expander trains work completely separated from each other.

\subsection{Air mass flow effect}

Air mass flow passes through the different stages of compressor train and is intercooled alternatively to be stored in a cavern. The compressed storage air goes into the combustors and after mixing by fuel, expands in turbines. Therefore the variation of power based on ambient air and cavern air mass flow in off-design condition which have been presented in Figure 6a and Figure $6 \mathrm{~b}$ respectively, can help the plant designers.

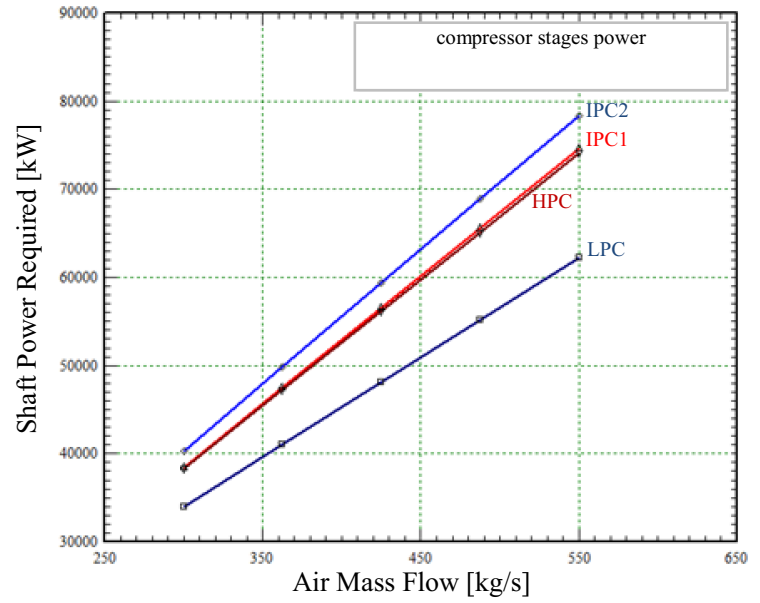

Figure 6a. Shaft power of compressor stages based on air mass flow

Increasing the stored air flow by $10.5 \%$ compared with the design value will increase the compressor total shaft power by $12 \%$ and this means a larger compressor capacity is required. It should be noted that the most part of power is generated in low pressure turbine and it is more sensitive on cavern air flow variation. If the flow of delivered air from cavern to turbine train decreases by $20 \%$ than the design value, the power generation would decrease accordingly by approximately $21.5 \%$ or $22 \mathrm{MW}$; $17 \mathrm{MW}$ of which is related to LPT and $5 \mathrm{MW}$ is associated with HPT.

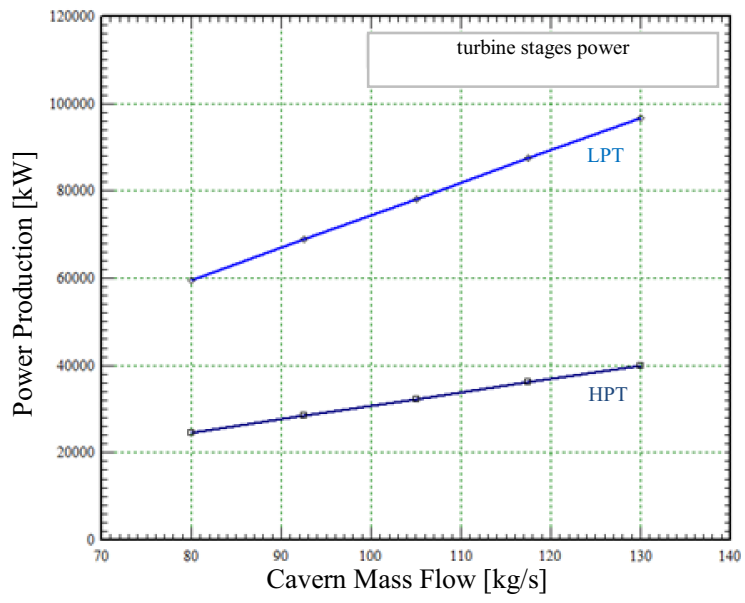

Figure 6b. Turbines power based on cavern air mass flow

\subsection{VAN and IGV effect}

One of the key parameters which plays a prominent role in compressor stability especially during the start up and shut down period is the percentage of inlet guide van (IGV) opening. It can be seen from Figure 7 that 50\% opening compared with fully (100\%) opening associated with design condition, can approximately lead to $13 \%$ decrease in both LP and HP compressors power consumption.

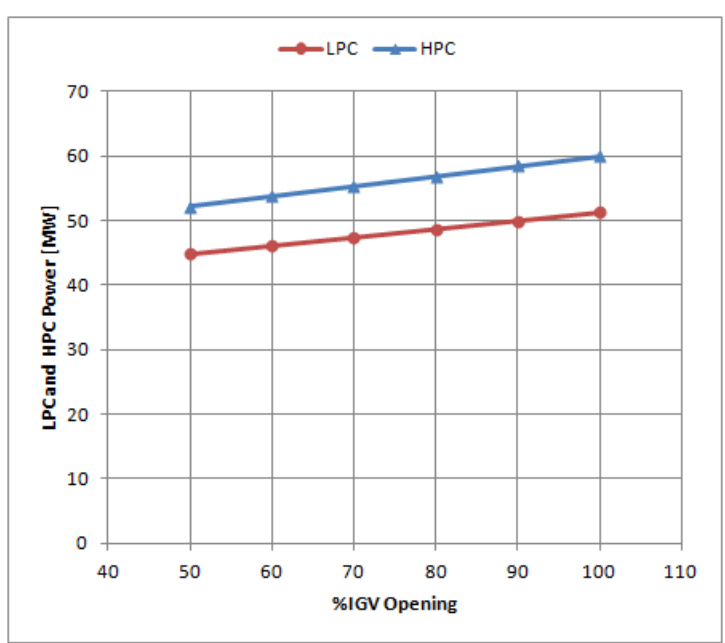

Figure 7. Decrease of compressor work based on inlet guide vane opening $\%$

As the same manner, the percentage of variable area nozzle (VAN) opening is an important control parameter for maintaining the turbine stable during the operation. As Figure 8 displays, a $50 \%$ increase of VAN opening relative to the design value, $100 \%$ opening, can make a 5 megawatts increase in LPT power generated. 


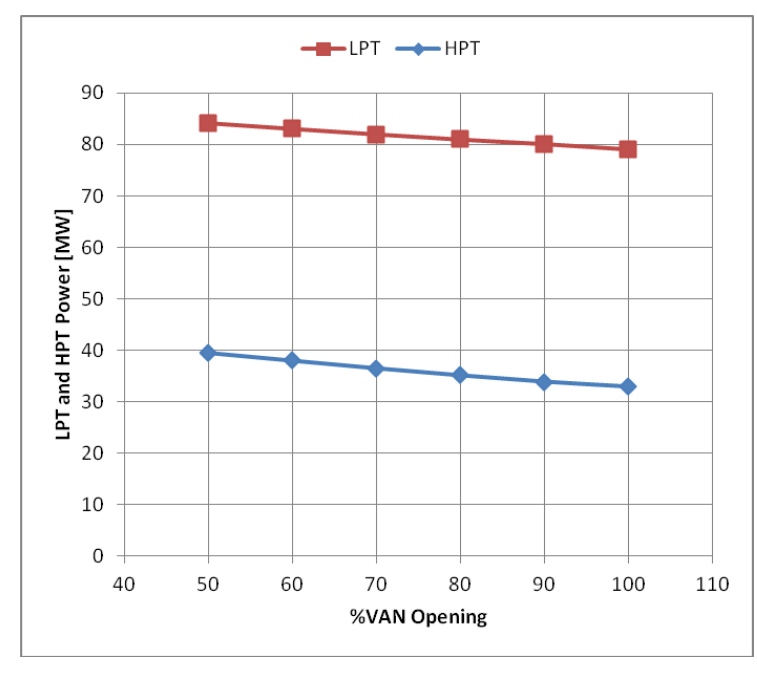

Figure 8. Increase of turbine work based on variable area nozzle opening $\%$

\section{Conclusion}

This study investigates the effect of key parameters on the design and operation of an optimized CAES plant via simulation. Using prior research as basis, the following conclusions can be drawn from this work:

1. Designers and operators should be well aware of the manner on which the performance of a CAES plant undergoing deviation from the design condition. To do this it is necessary to determine the effect of key parameters that can change the design conditions. The variation curves of design and operation parameters can be a good tool to awareness of appropriated changes.

2. The plant reaches its optimum value of heat rate in full load i.e. $4647 \mathrm{~kJ} / \mathrm{kWh}$. As it moves away from this state, the heat rate also increases. But compared with total value, the maximum variation is only $1.5 \%$ which is very little. That is why CAES plants are said to preserve their efficiency even in the part load.

3. When ambient temperature varies from 5 to 45 centigrade degree, total compression power increases from 238000 to $252000 \mathrm{~kW}$. In other words, bounding analysis of ambient temperature results in just $5.9 \%$ addition in required power. Moreover, because compressor and expander trains work completely separated from each other, this parameter does not have any effect on expander train. Therefore, the performance of CAES is almost independent of ambient temperature.

4. If the air flowing to turbine train decreases by $20 \%$ than the design value, the power generation would decrease accordingly by $21.5 \%$ or 22 MW; $17 \mathrm{MW}$ in LPT and $5 \mathrm{MW}$ in HPT. It is argued that the most part of power is generated in low pressure turbine and therefore, is more sensitive to cavern air flow variation.

\section{References}

1. H. Chen, TN. Cong, W. Yang, C. Tan, Y. Li, Y. Ding, Progress in electrical energy storage system-a critical review, Progress in Science J., 19: 291-312 (2009)

2. W. Liu, L. Liu, L. Zhou, J. Huang, Y. Zhang, G. Xu, Y. Yang, Analysis and optimization of a compressed air energy storage-combined cycle system, Entropy J., 16: 3103-3120 (2014)

3. X. Luo, J. Wang, M. Dooner, J. Clarke, C. Krupke, Overview of current development in compressed air energy storage technology, Energy Procedia J., 62: 603-611 (2014)

4. S. Succar, RH. Williams, Compressed air energy storage: theory, resources, and applications for wind power., Technical Rreport, Energy Systems Analysis Group, Princeton Environmental Institute, Princeton University (2008)

5. D. Connolly, H. Lund, P. Finn, B.V. Mathiesen, Leahy, Practical operation strategies for pumped hydroelectric energy storage (PHES) utilising electricity price arbitrage. Energy Policy J., 39: 4189-4196 (2011)

6. Y.S.H. Najjar, M.S. Zaamout, Performance analysis of compressed air energy storage (CAES) plant for dry regions, Energy Conversion and Management J., 39, 15: 1503-1511 (1998)

7. J. B. Greenblatt, S. Succar, D. C. Denkenberger, R. H. Williams, and R. H. Socolow, Baseload wind energy: modeling the competition between gas turbines, and compressed air energy storage for supplemental generation. Energy Policy J., 35: 14741492 (2007)

8. S.R. Shamshirgaran, M. Ameri, M. Khalaji, and H. Ghadamian, Design of a compressed air energy storage (CAES) power plant using the genetic algorithm, 4th Int. Conf. on Sustainable Energy and Environment (SEE), Nov. 23-25, Thailand, Bangkok (2011)

9. P. Vadasz, Compressed air energy storage, Encyclopaedia of Life Support Systems (EOLSS). Energy Storage Systems, ed. Yalsin Gogus, UNESCO Eolss Publishers. Oxford, UK., (invited chapter) (2002)

10. G. Lucas, H. Miller, Dresser-Rand compressed air energy storage solution, $2^{\text {nd }}$ Compressed Air Energy Storage (CAES) Conference \& Workshop, Oct. 2021, New York, Columbia University (2010) 